\title{
Creativity as affected by differential reinforcements and test instructions
}

\author{
ROY T. BAMBER, PAUL E. JOSE, and ROBERT BOICE \\ University of Missouri, Columbia, Missouri 65201
}

\begin{abstract}
One-hundred and eight college students were administered the Torrance Test of Creative Thinking, the Uses Test, and the Rotter I-E Scale in a study of effects of reward and test conditions upon creativity. Generally, differential instructions (as a test, as a game, or without instructions) and differential reinforcement (verbal praise, money, or no reinforcement) did not affect creativity as they had in prior research with children. Correlations of various measures of creativity with the I-E Scale suggest that subjects with an internally perceived locus of control were more fluent and flexible whereas those with an external locus were more elaborate.
\end{abstract}

Does reinforcement facilitate creativity or hinder it? Deci (1972a) suggests that there are two kinds of external reward which have opposite effects on an intrinsically motived activity: Controlling rewards (e.g., money) may lead a person to cognitively reevaluate an activity previously engaged in because of an intrinsic interest. Feedback rewards (e.g., verbal praise) may lead a person to feel competent and self-determined. Deci proposes that feedback rewards cannot be phenomenologically distinguished from feelings of competence and satisfaction which a person has when he is performing an activity for his own sake. Thus, according to Deci, controlling rewards decrease intrinsic motivation by leading a person to believe that control of his behavior passes from an internal to an external locus. Conversely, feedback rewards should enhance intrinsic motivation. So, to the extent that creativity is intrinsically motivated, controlling rewards should diminish it and feedback rewards should increase it.

Another way to facilitate performance might be to structure the situation to be perceived as play instead of work (Greene \& Lepper, 1974). Blumenfeld (1941) concludes that "neither the activity nor the person engaged in it is the decisive factor in determining its character as play or work. It is the state of mind or attitude of the person which makes it one or the other..." (pp. 472-473). It seems reasonable to suppose that tests of creativity can be structured to be perceived as either play or work. Again, to the extent that creativity is intrinsically motivated, controlling factors such as connotation of work should be detrimental. Conversely, a connotation of playfulness should enhance creativity.

In fact, the two factors of playfulness and verbal praise did produce a significant increase in creativity in children (Bamber, 1973). Bamber administered the

This research was funded by a University of Missouri Research Council Grant (URC NSF 1126). Reprints can be obtained from R. T. Bamber, Lewis \& Clark College, Godfrey, Illinois 62035.
"Circles" portion of the Torrance Test of Creative Thinking (Torrance, 1966) and the Uses Test (Getzels \& Jackson, 1962) to third through sixth graders. They were tested with differential instructions (as a test, as a game, or without orienting instructions) and with differential reinforcement (verbal praise, candy, or no reinforcement).

The present experiment was an attempt to extend Bamber's finding to college students. By necessity, money was substituted for candy with these wiser subjects. This was expected to be a difficult extension by virtue of the more complex incentive systems ingrained in these older subjects. Their behaviors were expected to be more mercenary and more specific to test situations than in the case of children.

\section{METHOD}

\section{Subjects}

Subjects were 108 college students, 54 male and 54 female, who served as part of a course requirement in introductory psychology classes. They were randomly assigned to one of 18 conditions, with six of each sex in each of the conditions.

\footnotetext{
Materials

Three research instruments were used: (a) The "Circles" portion of the research edition of the Torrance Test of Creative Thinking (Torrance, 1966) consisted of 36 circles of 1 in. diam in which subjects executed drawings of their choice within $10 \mathrm{~min}$. The circles were required to be the main part of the drawing. (b) An adaptation of the Uses Test (Getzels \& Jackson, 1962) consisted of the names of five objects (brick, pencils, paper clips, toothpicks, and sheet of paper) for which subjects were required to write as many different uses as they could within 15 min. (c) The Internal-External (I-E) scale (Rotter, Seeman, \& Liverant, 1962) comprised 29 pairs of statements and required subjects to choose one of each pair. This scale was implemented to measure each subject's perceived locus of control of reinforcements (internal or external).

\section{Procedure}

All subjects completed all three activities (Circles Test, Uses Test, and the I-E Scale), but half of the subjects were given the Circles Test first and the Uses Test second; half received the reverse order. All subjects completed the I-E Scale last. Tests were administered individually.
} 
Each of the three presentation modes involved specific instructions to the subjects: (a) Test condition-This situation was structured such that subjects were likely to perceive the session as one in which they were required to work. They were told that the experimenter wanted to find out how midwestern college students would do on the tests so that norms could be established. They were told that the first two tests were tests of creativity. (b) Play condition-This situation was structured such that subjects were likely to perceive the Circles and Uses Tests as fun. They were told that the experimenter was collecting norms for a new questionnaire (the I-E Scale) and that he wanted to find out how college students would answer the questions. Moreover, they were assured that all students who took the questionnaire should be in the same relaxed mood; they were told that the first two activities were fun to do (Circles and Uses Tests) and that these were actually tests of creativity. But they were also told that these were only instruments to induce a cheerful and relaxed mood. No subject questioned this rationale. (c) Neutral condition-Subjects in this condition were merely told that the experimenter had three activities for them to do, and they were then presented the activity instructions without further comment.

Subjects in the above three conditions were further divided the following three ways: (a) Verbal Praise-Subjects in this condition were given verbal praise on a variable interval schedule three times while they took the Circles Test and three times while they took the Uses Test. They were told that from time to time the experimenter would check on what they were doing to see if they were being creative and novel. Verbal praise, consisting of such sentences as "That's very good."; "That one is very nice."; "You were very creative here." was given at $3 \mathrm{~min}$, $7 \mathrm{mi} \mathrm{n}$, and $10 \mathrm{~min}$ during the Circles Test and statements of similar nature at $4 \mathrm{~min}, 9 \mathrm{~min}$, and $15 \mathrm{~min}$ for the Uses Test. (b) Material reinforcement-Subjects in this condition were told that from time to time the experimenter would check on what they were doing to see if they were being creative. The reward for creativity was stated as two quarter dollars for each time the experimenter checked and approved. They were told that the most money they could earn was $\$ 3.00$; in fact, all subjects in this condition were given $\$ 3.00$. The money was presented without verbal comment on the same schedule as in the verbal praise condition. (c) No reinforcement-Neither verbal praise nor money was given on the time checks in this condition.

Thus the experiment took the form of a 3 by 2 by 2 by 2 design (presentation mode by reinforcement by sex by order of test administration) for each of the following eight dependent variables: (a) Total score for the Circles Test ("Total Circles Score"), obtained by adding the raw scores for each of the four subscores. Within the Circles Test, the following four subscores were recorded according to instructions of Torrance (1968). (b) The fluency score was determined by counting the number of responses (some of which could include two or more circles). (c) Flexibility was assessed by counting the number of different categories into which responses fell according to Torrance's norms (1968). Examples of categories are: balls, containers, heavenly bodies, symbols, wheels. (d) Elaboration points were scored when the response was elaborated beyond the minimum necessary to express a basic idea (Torrance, 1968). (e) Responses were assigned originality values of zero, one, or two according to Torrance's norms. Bonus originality points were scored when the subject combined two or more circles into a single response. These were scored according to Torrance's criteria. (f) The actual number of circles completed, whether otherwise scoreable or not, were counted. (g) The Uses Test score was assessed by counting the number of different uses subjects gave for the Uses Test items and by adding bonus points for each use mentioned by $20 \%$ or less of the subjects (Getzels \& Jackson, 1962). (h) Finally, the total score for the I-E Scale was recorded. High I-E scores indicated that the perceived locus of control of reinforcements was external, and low scores indicated an internal locus of control (Rotter, Seeman, \& Liverant, 1962).
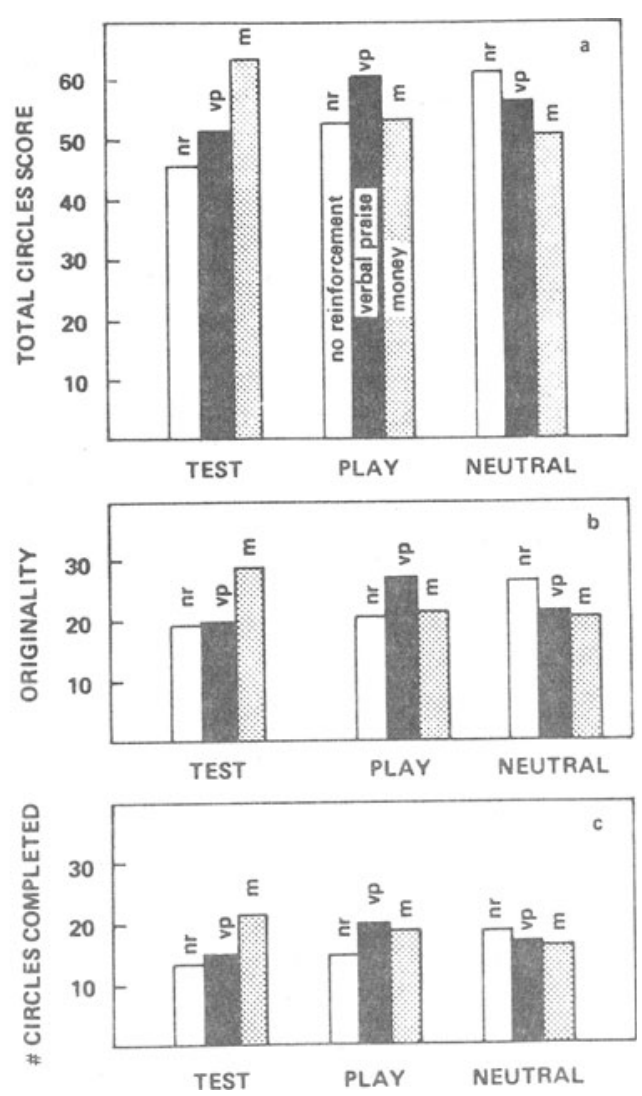

Figure 1. Results of the Torrance Test of Creative Thinking, Circles subtest, in three presentation modes: test (the creativity exercises were presented as fun), play (the material was presented as fun), neutral (the material was presented without comment). Presentation modes are shown within three dependent measures: total circles score (a), originality score (b), number of circles completed (c). The data are further subdivided according to reinforcement conditions: no reinforcement (nr), verbal praise (vp), and money (m), where each histogram is a mean value.

\section{RESULTS}

\section{Total Circles Score}

Analysis of variance indicated no significant main effect. Of the interactions, only the Presentation Mode by Reinforcement interaction was significant $(F=2.37$, $\mathrm{df}=4 / 72, p<.10)$. Simple effects analysis showed that there was a significant effect only for Reinforcement under the test condition $(F=3.48, d f=2 / 72, p<.05)$; a Duncan's multiple range test indicated that the mean for the test-money group was greater than the mean for the test-no reinforcement group (Figure 1a). The test-money and test-verbal praise groups did not differ significantly.

\section{Originality}

The main effect of order of test administration was significant $(F=4.13, \mathrm{df}=1 / 72, \mathrm{p}<.05)$ : Subjects who were given the Uses Test before the Circles Test scored significantly higher on the Circles Test than subjects who were given the tests in the reverse order. Simple effects 
analysis showed a significant effect only for the reinforcement variable under the test condition $(\mathrm{F}=3.28, \mathrm{df}=2 / 72, \mathrm{p}<.05)$. Money in the test condition (Figure 1b) was significantly more effective than verbal praise or no reinforcement according to a multiple range test.

\section{Number of Circles Completed}

The results for the number of circles completed score were similar to those for originality (Figure 1c). The order main effect was again significant $(F=2.91$, $\mathrm{df}=4 / 72, \mathrm{p}<.05)$ : Subjects given the Uses Test first completed significantly more circles than those given the Circles Test first. Once again, the only significance of the presentation mode and reinforcement conditions appeared in the test condition where money was the most effective reinforcer.

\section{Uses Test}

For the Uses Test, two interactions merit notice: Presentation Mode by Reinforcement $(F=2.49$, $\mathrm{df}=4 / 72, \mathrm{p}<.10)$, and Presentation Mode by Sex $(\mathrm{F}=3.52, \mathrm{df}=2 / 72, \mathrm{p}<.05)$. Simple effects analysis showed two significant findings: test-money females $(\bar{X}=56.8)$ were significantly $(F=4.38, \quad d f=2 / 72$, $\mathrm{p}<.025)$ more creative than females rewarded with money in the play condition $(\overline{\mathrm{X}}=30.2)$ and play-verbal praise males $(\bar{X}=55.5)$ were significantly $(F=5.39$, $\mathrm{df}=1 / 72, \mathrm{p}<.025)$ more creative than females in the same condition $(\bar{X}=34.2)$. Sex effects were not expected in any of the conditions and none were apparent with the other variables.

I-E scores correlated significantly with three Circles subscores of the Torrance test: fluency $(\mathrm{r}=-.247$, $\mathrm{p}<.05)$, flexibility $(\mathrm{r}=-.247, \mathrm{p}<.05)$ and elaboration $(\mathrm{r}=+.207, \mathrm{p}<.05)$. These indicate that subjects with an internally perceived locus of control were more fluent and flexible whereas those with an external locus were more elaborate in this test of creativity.

\section{DISCUSSION}

To most effectively motivate the college students in the present study, it was necessary to emphasize that they were being tested and to reward them with money. Verbal praise was no more effective than no reinforcement; both tended to be less effective than the combination of test and money conditions in producing creativity.
The salient finding of this study is the general lack of effects of reward or of test conditions upon creative performance. In contrast, Bamber (1973) achieved clear results with thirdthrough sixth-grade children. He found that the combination of a playful setting and verbal praise elicited the highest creativity. So Deci's $(1971,1972 a, 1972 b)$ ideas, that performance is best in self-controlled situations, apply to child ren (Greene \& Lepper, 1974) but not college students with the tests used here.

The striking difference between the two age groups might be primarily one of development. Perhaps by college age, certain creative facilities are fixed and some are more amenable to monetary control. College students may be much less capable of creativity in a playful situation, especially where it is contrived in an experimental setting. Orne (1969) has demonstrated the signal property of the laboratory in eliciting serious behaviors in college students, no matter what the intent of the experimenter.

In the present study, fluency, flexibility, and the ability to elaborate appeared as highly individual traits. That these are relatively inflexible compared to those of the children in Bamber's (1973) study is indicated by correlations with the I-E Scale. The suggestion is that, at college age, a flexible and fluent creator is more apt to emphasize internal motivation whereas the more elaborate creator is more responsive to external forces.

\section{REFERENCES}

BAmber. R. T. Play, interest, domestication, and creativity. Unpublished PhD Dissertation. University of Missouri. 1973.

BLLMENFELD. W. Observations concerning the phenomenon and origin of play. Philosophy and Phenomenological Research. 1941. 1. 470-478.

DECI. E. L. Effects of externally mediated rewards on intrinsic motivation. Journal of Personality and Social Psychology. 1971. 18. 105-115.

DECI. E. L. Intrinsic motivation, extrinsic reinforcement, and inequity. Joumal of Personality and Social Psychology, 1972. 22. $113-120$. (a)

DECI. E. L. Work-Who does not like it and why? Psychology Today. 1972. 6. 56-58. 92. (b)

Getzels. J. W.. \& JACKson, P. W. Creativity and itelligence. New York: Wilev, 1962.

Green, D., \& LePper, M. R. How to turn play into work. Psychology Today, 1974, 7, 49-54.

ORNE, M. T. Demand characteristics and the concept of quasicontrols. In R. Rosenthal \& R. L. Rosnow (Eds.). Artifact in behavioral research. New York: Academic Press, 1969.

Rotter. J., Seeman, M., \& Liverant, S. Internal versus external control of reinforcement: A major variable in behavior theory. In N. F. Washburne (Ed.). Decisions, values, and groups (Vol. 2). London: Pergamon Press. 1962.

Torrance. E. P. Torrance tests of creative thinking: Normstechnical manual. Princeton. N. J: Personnel Press, 1966.

Torrance. E. P. Torrance tests of creative thinking: Directions manual and scoring guide. Princeton. N. J: Personnel Press. 1968.

(Received for publication June 27, 1975.) 